\title{
Evaluation of intermetallic compound layer at aluminum/steel interface joined by friction stir scribe technology
}

\author{
Tianhao Wang a,c ${ }^{\text {a }}$ Harpreet Sidhar ${ }^{\text {a }}$, Rajiv S. Mishra ${ }^{\mathrm{a}, *}$, Yuri Hovanski ${ }^{\mathrm{b}}$, Piyush Upadhyay ${ }^{\mathrm{c}}$, Blair Carlson ${ }^{\mathrm{d}}$ \\ ${ }^{a}$ Center for Friction Stir Processing, Advanced Materials and Manufacturing Processes Institute, University of North Texas, Denton, TX 76203, USA \\ b Brigham Young University, Provo, UT 84602, USA \\ c Pacific Northwest National Laboratory, Energy Materials and Manufacturing, MSIN: K2-03, 902 Battelle Blvd., P.O. Box 999, Richland, WA 99352, USA \\ d General Motors Technical Center, Warren, MI 48093, USA
}

\section{H I G H L I G H T S}

- A theoretical model of Al-Fe intermetallic compound formation during friction stir welding of $\mathrm{Al} /$ steel is presented.

- Conventional Effective Heat of Formation model was modified for predicting sequence of intermetallic compound formation.

- Intermetallic compound thickness distribution along welded $\mathrm{Al} /$ steel interface was correlated to scribe trace.

- Defect-free lap welded joints of Al 6022T4 alloy and DP600 steel was achieved with an optimum joint efficiency of $\sim 97 \%$.
GRAPH ICA L A B STRACT

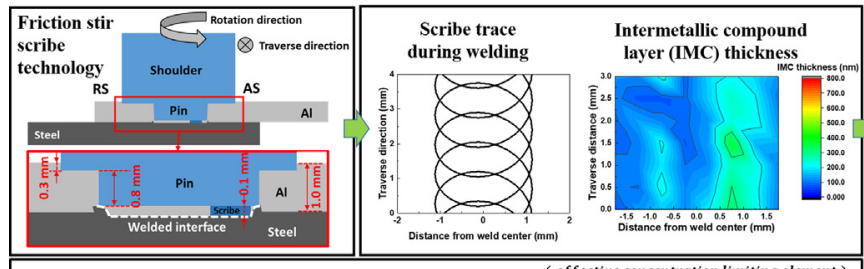

A modified EHF model with temperature factor: $\Delta H^{\prime}=\Delta H(T) \times\left(\frac{\text { effective concentration limiting element }}{\text { compound concentration limiting ele }}\right)$ for predicting formation of AI-Fe IMCs was developed in this study.

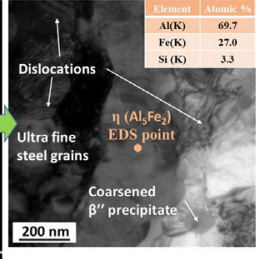

IMC morphology at Al/steel interface

\section{A R T I C L E I N F O}

\section{Article history:}

Received 16 January 2019

Received in revised form 10 April 2019

Accepted 11 April 2019

Available online 12 April 2019

\section{Keywords:}

Friction stir scribe technology

Dissimilar

Intermetallic

Thermodynamic

Kinetic

\begin{abstract}
A B S T R A C T
Heat input and high strain rate deformation during friction stir welding of aluminum and steel resulted in the diffusion-based formation of a $\mathrm{Fe}_{\mathrm{x}} \mathrm{Al}_{\mathrm{y}}$ intermetallic compound (IMC) layer. Compared with conventional friction stir welding tools, a friction stir scribe tool can reduce heat input significantly limiting the IMC layer thickness $(\sim 100-750 \mathrm{~nm})$. Friction stir scribe joined lap joints fractured either through the welded interface or within the base aluminum alloy on the loading side, depending on IMC layer thickness during tensile lap shear testing. In addition, a modified effective heat of formation model predicted that $\mathrm{Al}_{13} \mathrm{Fe}_{4}$ formed first at aluminum/steel interface and, during welding process, was substituted by $\mathrm{Al}_{5} \mathrm{Fe}_{2}$ with local silicon enrichment, which was verified via microstructural characterization.
\end{abstract}

(C) 2019 The Authors. Published by Elsevier Ltd. This is an open access article under the CC BY-NC-ND license (http://creativecommons.org/licenses/by-nc-nd/4.0/).

\section{Introduction}

Research on joining of Al alloys to steel is of great interest due to the growing demand for lightweight construction in the transportation industries [1]. The main barriers to achieving effective dissimilar bonding of $\mathrm{Al}$ and steel are the wide differences in their thermal and mechanical

\footnotetext{
* Corresponding author.

E-mail address: Rajiv.Mishra@unt.edu (R.S. Mishra).
}

properties, and the potential formation of brittle intermetallic compound (IMC) layer at the interface [2]. As one of the promising solid state joining methods, friction stir welding (FSW) is now studied widely and applied to a range of aluminum alloys and steels. FSW is characterized by relatively small heat input and limited concomitant IMC layer [3-5]. Previous studies on FSW of Al to steel led to identification of various intermetallic compounds including $\mathrm{FeAl}, \mathrm{Fe}_{4} \mathrm{Al}_{13}\left(\mathrm{FeAl}_{3}\right), \mathrm{Fe}_{2} \mathrm{Al}_{5}$ and $\mathrm{FeAl}_{4}$ [5-7]. The presence of IMC layer leads to a decrease of mechanical properties of the weld $[4,5,8,9]$. In addition, the IMC layer discontinuity 

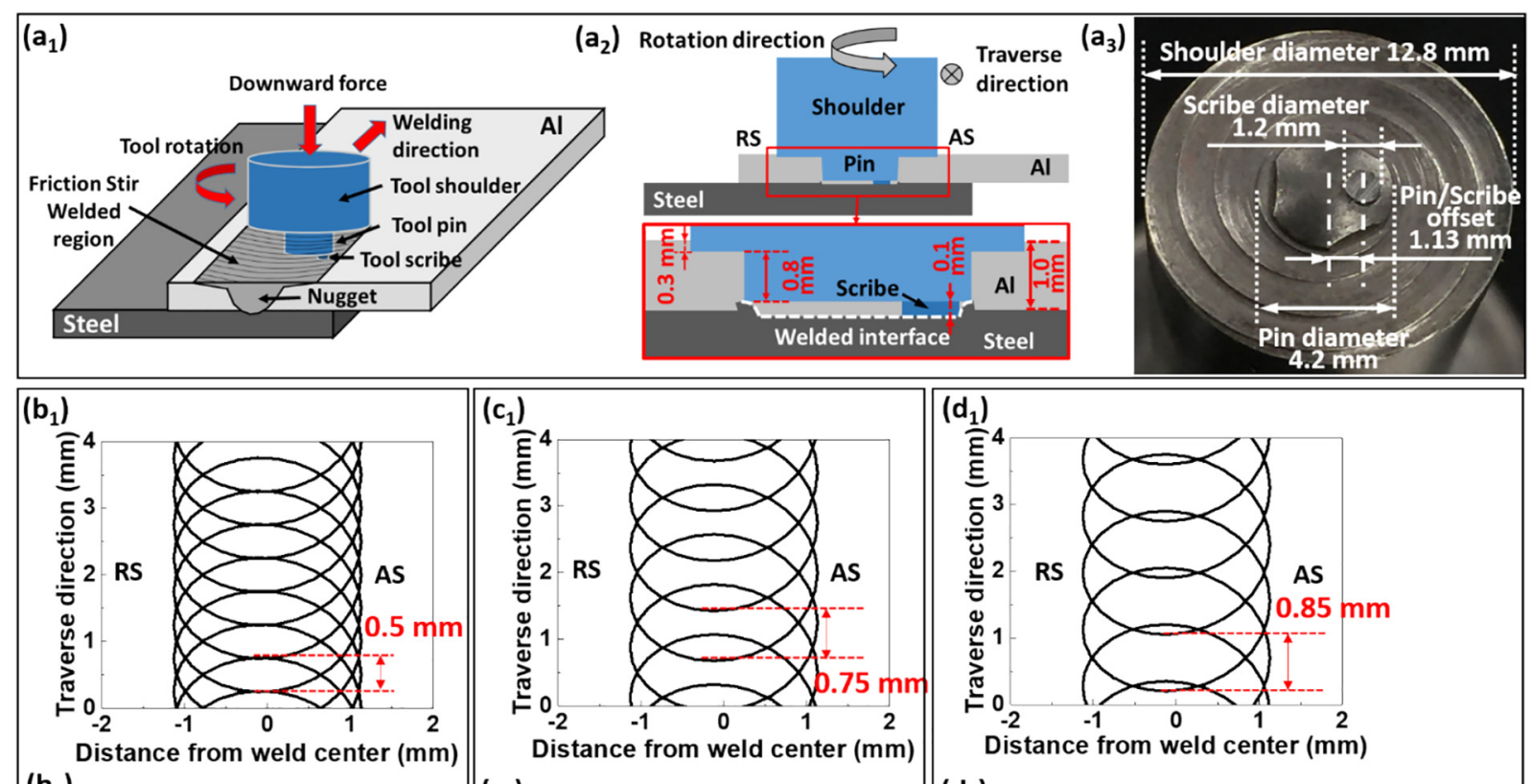

$\left(b_{2}\right)$
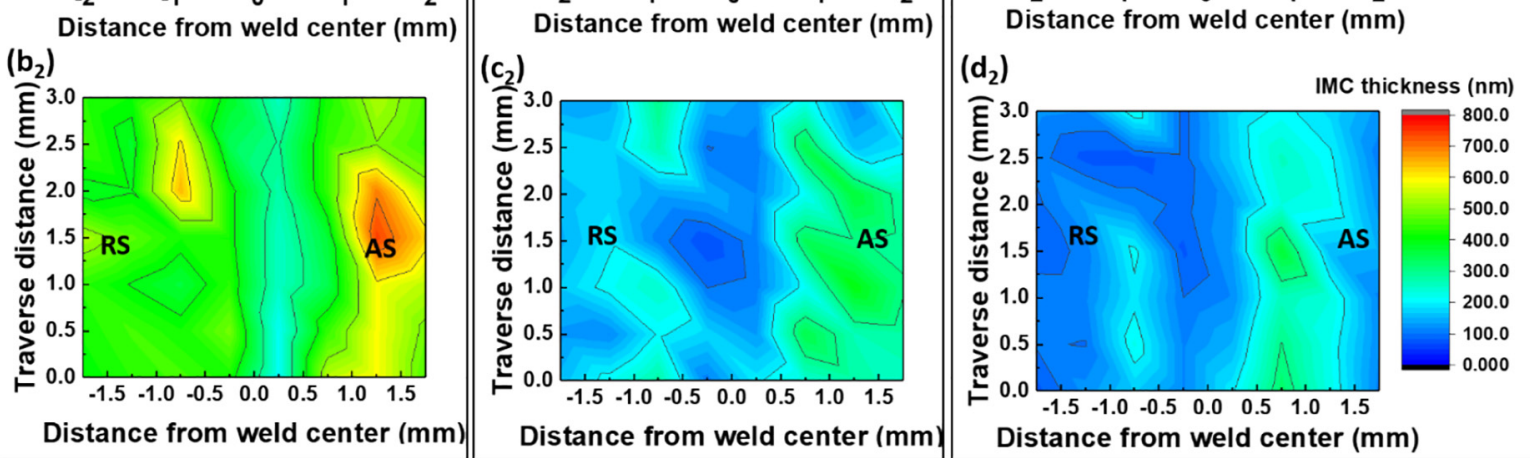

Distance from weld center $(\mathrm{mm}$

Distance from weld center $(\mathrm{mm})$

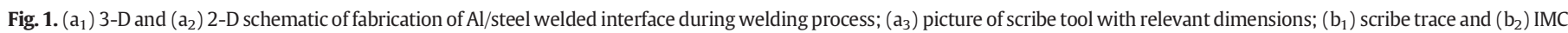
thickness distribution of run $1 ;\left(c_{1}\right)$ scribe trace and $\left(c_{2}\right)$ IMC thickness distribution of run 2 and $\left(d_{1}\right)$ scribe trace and $\left(d_{2}\right)$ IMC thickness distribution of run 3 .

was also observed in bonding of $\mathrm{Al}$ and steel by friction stir spot welding [9] and friction welding [10]. However, the mechanism of Al-Fe IMC formation and growth was not well investigated.

In this study, friction stir scribe (FSS) technology [11-13] was applied for lap welding of AA6022-T4 (Al 6022-T4 alloy) and DP600 steel sheets. FSS technique utilizes a small offset cutting tool (scribe) at the tip of the FSW pin. As the tool plunges into the $\mathrm{Al} /$ steel stackup, the cutting tool machines off the surface of steel while the conventional portion of the tool plastically deforms the Al alloy. Because of this unique method of machining and FSW, as compared to conventional FSW, a significantly reduced volume of steel is engaged, with concomitant decrease of heat input and IMC layer thickness at the $\mathrm{Al} /$ steel interface. Observation of the weld cross section displayed the variation of IMC layer thickness with scribe trace during the welding process. Fractography revealed that IMC formed regionally at the $\mathrm{Al} /$ steel interface for welds fracturing through the welded interface. Al-Fe IMC formation mechanisms during FSS were evaluated. The aims of this work were: (1) to verify intermetallic compound composition and morphology at the welded $\mathrm{Al} /$ steel interface, (2) to elucidate the $\mathrm{Al}$ - Fe IMC formation mechanism during FSS technology, and (3) to clarify the effect of IMC layer morphology (thickness and distribution) on dissimilar joint strength and fracture modes.

\section{Materials and methods}

AA6022-T4 aluminum alloy sheets (1.0 mm thickness) were lap welded to DP600 steel sheets (1.2 mm thickness) by the FSS tool. AA6022-T4 sheet was put on the top of DP600 sheet during welding. The tool body was made of $\mathrm{H} 13$ tool steel with M42 cobalt steel scribe, a scroll-featured shoulder diameter of $12.8 \mathrm{~mm}$, triangular pin diameter of $4.2 \mathrm{~mm}$, cylindrical scribe diameter of $1.2 \mathrm{~mm}$, pin height of $0.8 \mathrm{~mm}$, scribe height of $0.1 \mathrm{~mm}$, and offset between pin center to scribe center of $1.13 \mathrm{~mm}$ (Fig. $1\left(\mathrm{a}_{3}\right)$ ). Detailed information regarding the scribe tool was provided in Hovanski et al.'s patent [11]. Mechanical properties of the base materials are listed in Table 1 . Five tensile samples were prepared and tested for base AA6022-T4 and DP600, respectively. Three sets of welding process parameters with different rotation rate $(\mathrm{R})$ and traverse speed $(\mathrm{T})$ and constant plunge depths $\left(\mathrm{P}_{\mathrm{d}}\right)$ of $1.2 \mathrm{~mm}$ and tilt angle $\left(\mathrm{T}_{\mathrm{A}}\right)$ of $0.5^{\circ}$ were applied for the three welds, as listed in Table 2. Note that $P_{d}$ represented total plunge depth into material, and shoulder plunge into material was around $0.3 \mathrm{~mm}$ (Fig. $1\left(\mathrm{a}_{2}\right)$ ). Al alloy sheets were positioned on the advancing side (AS) and steel sheets were placed as the retreating side (RS) (Fig. 1( $\left.\mathrm{a}_{2}\right)$ ).

Tensile lap shear tests on the welded joints were performed using ASTM D1002-10. The width of the test samples was $25.4 \mathrm{~mm}$. For each welding condition, five tensile test samples were prepared and tested to confirm stability of each welding process. Cross sections of welds were observed by scanning electron microscope (SEM), especially the IMC layer at the Al/steel interface. To investigate the distribution of IMC layer under different welding parameters, seven cross sections with spacing of $0.5 \mathrm{~mm}$ for each run were observed and IMC layers

Table 1

Mechanical properties of AA6022-T4 and DP600 steel.

\begin{tabular}{llll}
\hline Base materials & Yield strength/MPa & Tensile strength/MPa & Elongation/\% \\
\hline AA6022-T4 Al alloy & $141 \pm 12$ & $258 \pm 8$ & $47 \pm 4$ \\
DP600 steel & $435 \pm 11$ & $665 \pm 9$ & $42 \pm 2$ \\
\hline
\end{tabular}


Table 2

Welding parameters for runs 1,2 and 3.

\begin{tabular}{lllll}
\hline Run & $\mathrm{R}($ round $/ \mathrm{min})$ & $\mathrm{T}(\mathrm{mm} / \mathrm{min})$ & $\mathrm{P}_{\mathrm{d}}(\mathrm{mm})$ & $\mathrm{T}_{\mathrm{A}}\left({ }^{\circ}\right)$ \\
\hline 1 & 2000 & 1000 & 1.2 & $0.5^{\circ}$ \\
2 & 2000 & 1500 & 1.2 & $0.5^{\circ}$ \\
3 & 2000 & 1700 & 1.2 & $0.5^{\circ}$ \\
\hline
\end{tabular}

were measured by SEM. In addition, scribe trace was calculated and plotted to correlate to IMC thickness distribution. The spiral shape of scribe trace during FSW was simplified tilt of $0^{\circ}$ in the calculation. To identity the IMC component at the interface, transmission electron microscopy (TEM) equipped with energy-dispersive X-ray spectroscopy (EDS) was applied. Fractography of tested joints was observed and analyzed by SEM and EDS.

\section{Results and discussion}

The scribe feature removes the steel surface forming hook like features on either side of the tool (Fig. $1\left(\mathrm{a}_{2}\right)$ ). Aluminum alloy flows under the pin bottom, and the welded interface is formed between aluminum alloy and steel (Fig. $1\left(\mathrm{a}_{2}\right)$ ). Three different traces of scribe center were produced by different welding traverse speeds (Fig. 1( $b_{1}, c_{1}$ and $\left.\mathrm{d}_{1}\right)$ ). The ratio of traverse speed to rotation rate was defined as $T / R$, which indicated the distance the scribe traversed in one rotation. Since the $1.2 \mathrm{~mm}$ scribe diameter was larger than the T/R values of run $1(0.5 \mathrm{~mm})$, run $2(0.75 \mathrm{~mm})$ and run $3(0.85 \mathrm{~mm})$, the processed regions of consequent rotations overlapped for runs 1,2 and 3. Overlapping decreased with increasing traverse speed: run $1>$ run $2>$ run 3 . In each run, overlapping was asymmetrical in the transverse direction and periodical in the traverse direction. The AS region had more overlapping than $\mathrm{RS}$ region, and the center region along the traverse direction had the smallest overlapping. Overlapping fluctuated periodically along the traverse direction and additional frictional heat was produced between scribe and steel sheet with greater overlapping. In addition, strain is substantially higher on the AS than RS [14]. IMC formed via thermal and mechanical cycles during the welding process. Therefore, the overlapping (Fig. $1\left(b_{1}, c_{1}\right.$ and $\left.d_{1}\right)$ ) determines the horizontalplane distribution of IMC thickness at $\mathrm{Al} /$ steel interface (Fig. $1\left(\mathrm{~b}_{2}, \mathrm{c}_{2}\right.$ and $\left.\mathrm{d}_{2}\right)$ ). Overall IMC thickness decreased with increase in traverse speed and resultant decrease in peak temperature. IMC thickness distributions of runs 1, 2 and 3 were similar in shape, IMC thickness at AS (right region) was thicker than that at RS (left region), and IMC thickness at the weld center tended to be thin. In addition, IMC thickness fluctuated periodically along the traverse direction.

Different traverse speeds also provided different heat and deformation input for top aluminum alloy sheets, and can reduce strength of the starting tempered (T4) aluminum alloy. Microhardness results exhibited no significant difference in stir zone (SZ) and thermomechanically affected zone (TMAZ) for three different traverse speeds (Fig. 2(a)). For heat affected zone (HAZ), run 1 had lower strength than runs 2 and 3 due to its lower rate of cooling at lower welding speed. Tensile shear tests were conducted on runs 1, 2 and 3 to study the effect of IMC thickness on bonding strength. Test results on base aluminum alloy and runs 1-3 are listed in Table 3. Note that width of test samples was $25.4 \mathrm{~mm}$. One of five test samples for each condition was selected to compare with each other. Load-extension curves of base aluminum alloy sheet and runs 1, 2 and 3 are displayed in Fig. 2(b). Run 1 (fractured along path 1) had lower strength than base aluminum since hook at AS reduced effective aluminum thickness, and the processed aluminum lost its starting tempered strength. For runs 2 and 3 (fractured along path 2), strength of run 2 was higher than run 3 , because of the more complete formation of IMC at run 2 than that at run 3 to bond aluminum and steel sheets. Note that when IMC layer was continuous and thicker than several microns at $\mathrm{Al} /$ steel interface, joint strength increased with a reduction in IMC thickness. When IMC layer was discontinuous, joint strength increased with completeness of IMC layer. Two fracture paths during tensile shear tests are shown in Fig. 2 (c): (1) path 1 represents fracture at the loading side of aluminum (boundary of SZ/TMAZ) and (2) path 2 represents fracture through the welded $\mathrm{Al} /$ steel interface. Note that hook heights for runs $1-3$ were all $\sim 50 \mu \mathrm{m}$, therefore, the fracture mode was determined by completeness of $\mathrm{Al} /$ steel bonding interface. Joint efficiency (JE) was calculated to show joint strength compared with base material and was calculated as: $J E=\left(P_{j} / P_{w}\right) \times 100$, where $P_{j}$ is the peak load of standard test sample of joint and $\mathrm{P}_{\mathrm{w}}$ is the peak load of weaker base material. According to the mechanical properties stated in Table 1, aluminum alloy was considered to be weaker base material in this study. Optimum joint efficiency was obtained from run 2, and average joint efficiency for run 2 was calculated as $\sim 98 \%$ according to data listed in Table 3.

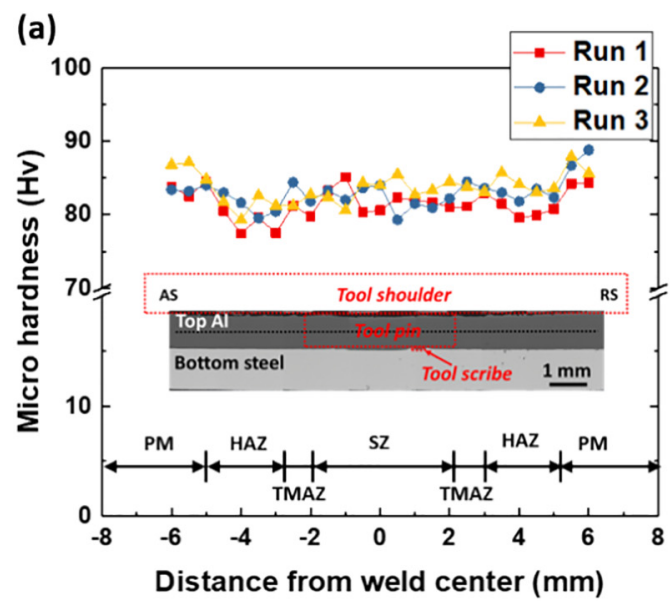

(b)

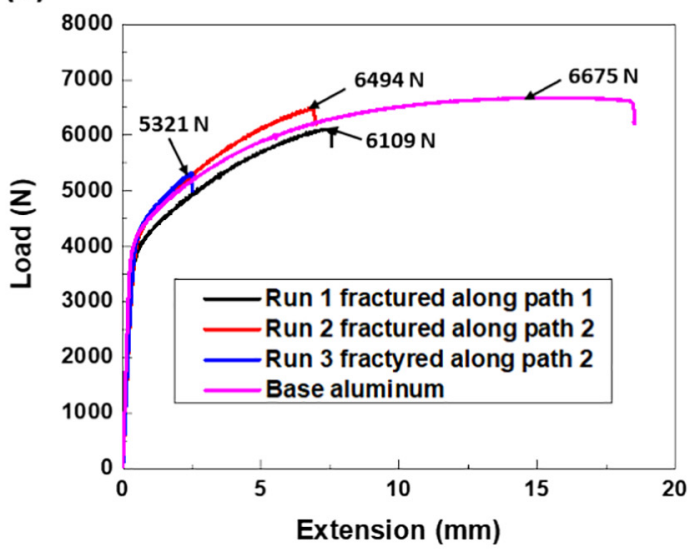

(c) Test

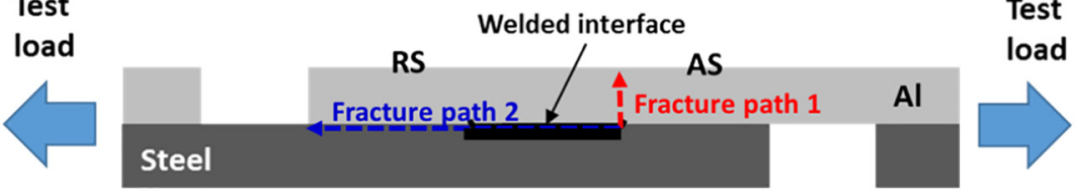

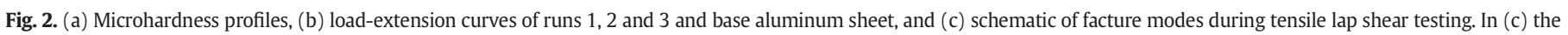
fracture paths are denoted as: (1) fracture path 1 indicates joint breakage at loading side of aluminum, and (2) fracture path 2 indicates joint breakage through welded interface. 
Table 3

Peak load and extension of tensile tests on base aluminum alloy and joints of runs 1-3.

\begin{tabular}{lll}
\hline Material & Peak load $(\mathrm{N})$ & Extension $(\mathrm{mm})$ \\
\hline Base AA6022-T4 & $6553 \pm 203$ & $23 \pm 5$ \\
Run 1 & $6002 \pm 292$ & $9 \pm 4$ \\
Run 2 & $6412 \pm 307$ & $10 \pm 3$ \\
Run 3 & $5405 \pm 169$ & $5 \pm 3$ \\
\hline
\end{tabular}

Run 1 had higher IMC thickness contour than that of runs 2 and 3. Still, IMC of run 1 was too thin to provide a path for crack propagation. As shown in Fig. $3\left(a_{1}\right)$ and $\left(b_{1-3}\right)$, fracture path 1 appeared in the test sample of run 1 . Further observation on the fractured sample of run 1 showed that the crack also propagated along the welded interface (fracture path 2 ) but terminated in aluminum just above the IMC layer (Fig. 3 $\left.\left(b_{3}\right)\right)$. This termination might be because the IMC layer was too thin to show brittleness. For runs 2 and 3, samples fractured through path 2 . The IMC thickness contours of runs 2 and 3 were lower than that of run 1 . IMC not forming completely at certain regions between aluminum and steel sheets during FSW for runs 2 and 3 provided a path for crack propagation through path 2 . Fracture surface of broken samples of runs 2 and 3 were observed by back-scattered SEM. As shown in Fig. $3\left(c_{1}\right)$, the surface of the fractured steel portion of run 2 confirms that most of the steel was covered by aluminum (dark region) and the remaining light region was steel. The light region implied that $\mathrm{Al}$ was not bonded well with steel in this region. Similarly, the surface of the fractured steel part of run 3 shows light and dark regions. The area of light region is larger for run 3 than run 2. This is because the IMC contour of run 3 was even lower than that of run 2, and aluminum was less bonded with steel for run 3 than for run 2 (Fig. $3\left(d_{1}\right)$ ) which
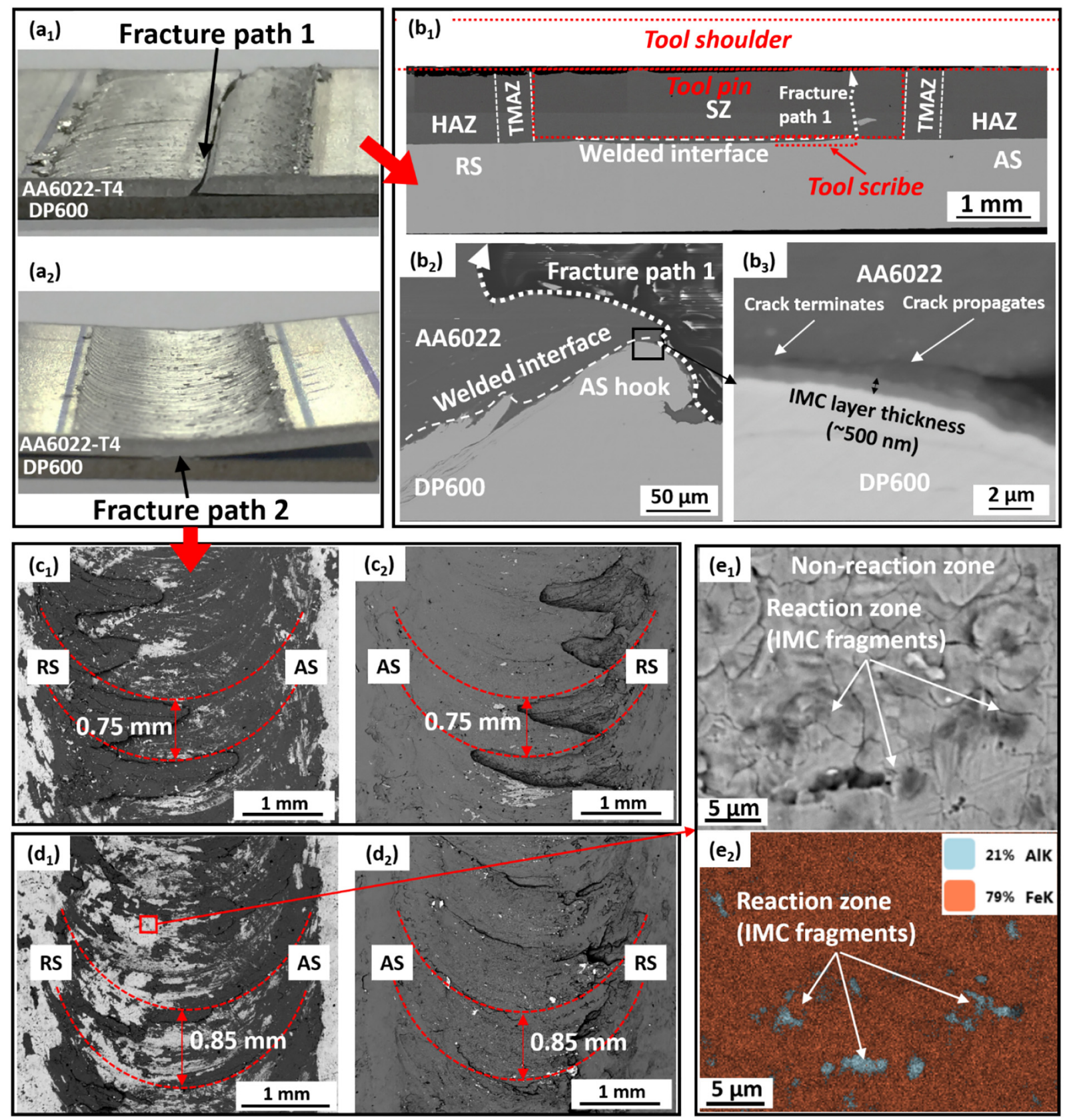

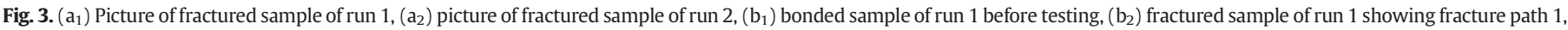

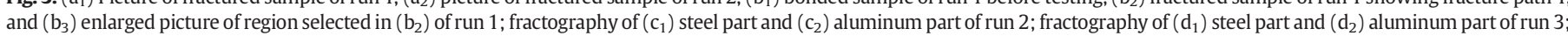
$\left(e_{1}\right)$ SEM and $\left(e_{2}\right)$ EDS analysis on steel region (light region shown in $\left(d_{1}\right)$ ). 
accounts for the reduced peak load and extension of run 3 in Fig. 2(c). In addition, periodic features produced by scribe movement corresponded with scribe traces of runs 2 and 3. EDS analysis was applied to study the regions uncovered by aluminum in Fig. $3\left(c_{1}\right)$ and $\left(d_{1}\right)$, as shown in Fig. 3 $\left(e_{1,2}\right)$. IMC fragments were observed at certain regions (reaction zone). The non-reaction zone implied that certain areas did not have sufficient time and temperature for significant chemical reaction to occur between steel and aluminum.

A theoretical model of $\mathrm{Al}-\mathrm{Fe}$ IMC formation mechanisms during FSW as presented in Fig. 4(a) proposes that chemical reaction and diffusion resulted in IMC formation and growth via thermal and mechanical cycles during FSW. Chemical reaction (thermodynamic) models including Walser-Bené $[15,16]$ and effective heat of formation (EHF) [17] were applied to predict IMC formation sequence. The Walser-Bené model indicates that the phase immediately adjacent to low-temperature eutectic is formed first $\left(\mathrm{Al}_{13} \mathrm{Fe}_{4}\right.$ for Al-Fe phase diagram). Additionally, the driving force for a chemical reaction can be represented via the change in Gibbs free energy $(\Delta \mathrm{G})$ :

$\Delta \mathrm{G}=\Delta \mathrm{H}-(\mathrm{T} \times \Delta \mathrm{S})$

where $\Delta \mathrm{H}$ is the change in enthalpy, $\mathrm{T}$ is temperature and $\Delta \mathrm{S}$ is the change in entropy. The value of T $\Delta S$ is approximately zero for FSW (solid state joining) [18]; therefore, Eq. (1) was rewritten as:

$\Delta \mathrm{G} \approx \Delta \mathrm{H}$

The EHF model considers element concentration and assumes that the chemical reaction happens in an effective element concentration at the growing interface. The effective heat of formation $\left(\Delta \mathrm{H}^{\prime}\right)$ for each possible IMC is calculated as:

$\Delta \mathrm{H}^{\prime}=\Delta \mathrm{H} 0 \times\left(\frac{\text { effective concentration limiting element }}{\text { compound concentration limiting element }}\right)$

where $\Delta \mathrm{H}^{0}$ is the enthalpy change or heat of formation in the standard state. The values of $\Delta H^{0}\left(\Delta G^{0}\right)$ were reported in different references: $\mathrm{Al}_{5} \mathrm{Fe}_{2}$ should form first based on [19], and $\mathrm{Al}_{13} \mathrm{Fe}_{4}\left(\mathrm{Al}_{3} \mathrm{Fe}\right)$ should form first based on [20-22]. The actual chemical reactions happen at a given temperature $(\mathrm{T})$ rather than at a standard state, and the temperature factor should be included. Therefore, in this study, a modified EHF model involving temperature factor is presented as:

$\Delta \mathrm{H}^{\prime}(\mathrm{T})=\Delta \mathrm{H}(\mathrm{T}) \times\left(\frac{\text { effective concentration limiting element }}{\text { compound concentration limiting element }}\right)$

where $\Delta H^{\prime}(T)$ is the effective heat of formation at a given temperature $T$, and $\Delta H(T)$ is the heat of formation at a given temperature (T). Based on the equations from [23]:

$$
\begin{aligned}
& \Delta \mathrm{H}(\mathrm{T})\left(\mathrm{Al}_{13} \mathrm{Fe}_{4}\right)=-38,733.42+16.05 \mathrm{~T}-0.94 \times 1028 \times \mathrm{T}^{-9} \\
& \Delta \mathrm{H}(\mathrm{T})\left(\mathrm{Al}_{5} \mathrm{Fe}_{2}\right)=-40,141.13+15.04 \mathrm{~T}-0.88 \times 1028 \times \mathrm{T}^{-9} \\
& \Delta \mathrm{H}(\mathrm{T})\left(\mathrm{Al}_{2} \mathrm{Fe}\right)=-39,687.25+13.75 \mathrm{~T}-0.82 \times 1028 \times \mathrm{T}^{-9}
\end{aligned}
$$

$\Delta \mathrm{H}(\mathrm{T})$ curves for $\mathrm{Al}_{13} \mathrm{Fe}_{4}, \mathrm{Al}_{5} \mathrm{Fe}_{2}$, and $\mathrm{Al}_{2} \mathrm{Fe}$ are plotted from 600 to $1500 \mathrm{~K}$ in Fig. 4(b). At a temperature of $798 \mathrm{~K}$ (peak temperature in $\mathrm{Al} /$ steel interface during $\mathrm{FSW}), \Delta \mathrm{H}^{\prime}(\mathrm{T})$ curves for $\mathrm{Al}_{13} \mathrm{Fe}_{4}, \mathrm{Al}_{5} \mathrm{Fe}_{2}$, and
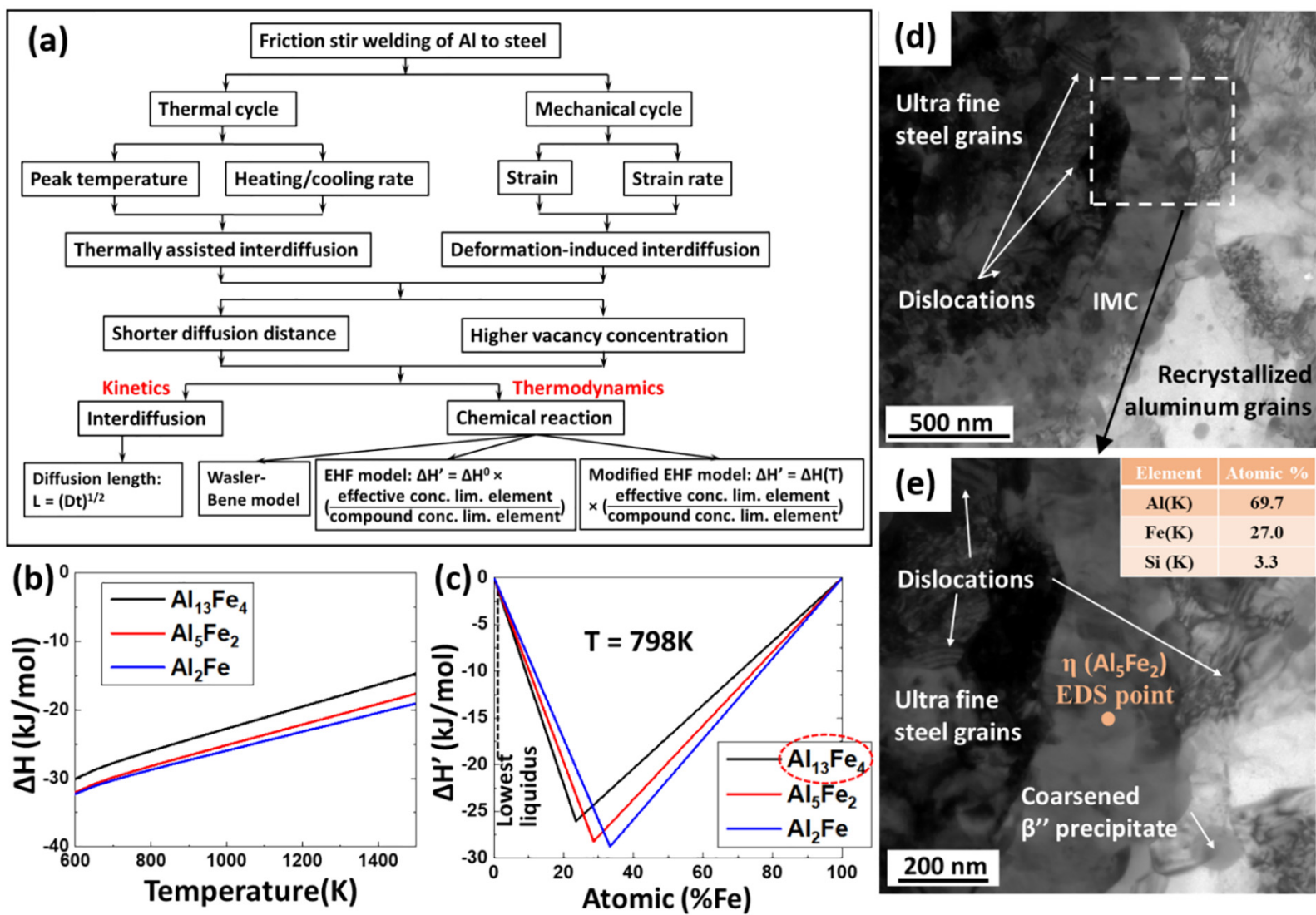

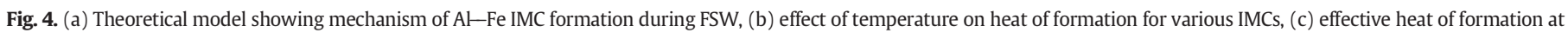
$798 \mathrm{~K}$ for various IMCs, (d) TEM image on Al/steel interface, and (e) enlarged picture on white dash rectangle in (d) and EDS point analysis on IMC layer. 
$\mathrm{Al}_{2} \mathrm{Fe}$ are plotted in Fig. 4(c). At the lowest liquid composition for $\mathrm{Al}-\mathrm{Fe}$ system (at.\% Fe), $\mathrm{Al}_{13} \mathrm{Fe}_{4}$ has the lowest $\Delta \mathrm{H}^{\prime}(\mathrm{T})$ value, so $\mathrm{Al}_{13} \mathrm{Fe}_{4}$ is predicted to form first based on the modified EHF model.

The interdiffusion (kinetic) model was applied for IMC thickness prediction according to diffusion coefficient (D) and thermal cycle. D of Fe into $\mathrm{Al}$ matrix is much higher than $\mathrm{D}$ of $\mathrm{Al}$ into $\mathrm{Fe}$, therefore, interdiffusion between $\mathrm{Al}$ and $\mathrm{Fe}$ can be simplified as one direction diffusion from Fe into $\mathrm{Al}$ [24]. After initial IMC $\left(\mathrm{Al}_{13} \mathrm{Fe}_{4}\right)$ formation between $\mathrm{Al} /$ steel, the diffusion medium becomes the initial IMC $\left(\mathrm{Al}_{13} \mathrm{Fe}_{4}\right)$ itself. The values of $\mathrm{D}$ for $\mathrm{Al}$ and $\mathrm{Fe}$ atoms into $\mathrm{Al}_{13} \mathrm{Fe}_{4}$ decreased significantly to $8.3 \times 10^{-14} \mathrm{~m}^{2} \mathrm{~s}^{-1}$ and $9.4 \times 10^{-14} \mathrm{~m}^{2} \mathrm{~s}^{-1}$ respectively, even at $1173 \mathrm{~K}$, and they would be even lower at typical FSW temperature $(900 \mathrm{~K})$ [25]. $\mathrm{Al}_{5} \mathrm{Fe}_{2}$ formed on the basis of initial IMC $\left(\mathrm{Al}_{13} \mathrm{Fe}_{4}\right)$ along with the diffusion of $\mathrm{Fe}$ atoms into $\mathrm{Al}_{13} \mathrm{Fe}_{4}$ IMC layer [26]. The $\mathrm{D}$ value of Fe atoms into $\mathrm{Al}_{5} \mathrm{Fe}_{2}$ is $2.1 \times 10^{-12} \mathrm{~m}^{2} \mathrm{~s}^{-1}$ at $1173 \mathrm{~K}$ [25], which is higher than $\mathrm{D}$ of $\mathrm{Fe}$ atoms into $\mathrm{Al}_{13} \mathrm{Fe}_{4}$. Therefore, $\mathrm{Al}_{5} \mathrm{Fe}_{2}$ layer grows faster and takes over the initial $\mathrm{Al}_{13} \mathrm{Fe}_{4}$ layer, because structural vacancies exist in the direction of the longest axis of the orthorhombic crystal lattice for $\mathrm{Al}_{5} \mathrm{Fe}_{2}$ [27]. This is similar to what has been reported for $\mathrm{Al}-$ Steel resistance spot welds [28]. IMC thickness can be predicted based on D and thermal cycle during FSW:

$\mathrm{L}=(\mathrm{Dt})^{1 / 2}$

where $\mathrm{L}$ is diffusion length (IMC thickness), $\mathrm{t}$ is the time gap when FSW temperature is higher than diffusion requirement. In this study, L value decreased with increase in traverse speed along with resultant t decrease. Furthermore, mechanical cycle (local strain/stress introduced by pin and scribe) contributed to either chemical reaction or interdiffusion during FSW (Fig. 4(a)). This is because high deformation can provide higher diffusion vacancy and shorter diffusion distance $[29,30]$.

To confirm the composition of IMC at the welded $\mathrm{Al} /$ steel interface, TEM and EDS point analyses were conducted (Fig. 4(d) and (e)). Steel grains were refined and dislocations were produced under hightemperature deformation by scribe during FSW. Dislocations at the interface of steel/IMC provided a path for Fe atoms to diffuse into IMC to make it grow. Aluminum grains adjacent to IMC were recrystallized and dislocations existed in the aluminum matrix after FSW, and $\beta^{\prime \prime}$ precipitates in aluminum matrix coarsened due to heat input during FSW. In addition, EDS point analysis at IMC shows that $\eta\left(\mathrm{Al}_{5} \mathrm{Fe}_{2}\right)$ phase formed between $\mathrm{Al} /$ steel with local silicon enrichment (Fig. 4(e)).

\section{Conclusions}

(1) Defect-free lap welded joint of AA6022-T4 and DP600 was achieved by friction stir scribe technology, and joint efficiency reached $\sim 98 \%$. Welds broke at the loading side of Al with IMC layer thickness of $\sim 350-750 \mathrm{~nm}$; and welds broke along the welded interface with IMC thickness of $\sim 100-350 \mathrm{~nm}$. In addition, horizontal-plane distribution of IMC thickness along $\mathrm{Al} /$ steel interface was determined by welding parameters and resultant scribe trace.

(2) A theoretical model of IMC formation during FSW was presented, and a modified EHF model was developed to predict IMC formation sequence. During $\mathrm{FSW}, \mathrm{Al}_{13} \mathrm{Fe}_{4}$ formed first, and then was taken over by $\mathrm{Al}_{5} \mathrm{Fe}_{2}$ via subsequent diffusion of $\mathrm{Fe}$ atoms into $\mathrm{Al}_{13} \mathrm{Fe}_{4}$ and local silicon enrichment was observed in IMC layer, which was verified by microstructural characterization.

\section{Credit}

TW and HS conducted the experiments. RSM, YH, PU and BC designed the work. TW and RSM drafted the manuscript and all the authors contributed to the final paper.

\section{Acknowledgments}

This work was supported under the NSF-IUCRC grant for Friction Stir Processing (NSF-IIP 1157754). The additional support of Boeing, General Motors, Pacific Northwest National Laboratory, Army Research Laboratory and Rolls-Royce Corporation for the University of North Texas (UNT) site is acknowledged. This report was prepared as an account of work sponsored by an agency of the US Government. The views and opinions of the authors expressed herein do not necessarily state or reflect those of the US Government or any agency thereof. We also acknowledge the UNT Materials Research Faculty (MRF).

\section{Data availability statement}

The raw/processed data required to reproduce these findings cannot be shared at this time as the data also forms part of an ongoing study.

\section{References}

[1] S. Fukumoto, T. Inuki, H. Tsubakino, K. Okita, M. Aritoshi, T. Tomita, Mater. Sci Technol. 13 (1997) 679-686, https://doi.org/10.1179/mst.1997.13.8.679.

[2] K. Martinsen, S. Hu, B. Carlson, CIRP Ann. Manuf. Technol. 64 (2015) 679-699, https://doi.org/10.1016/j.cirp.2015.05.006.

[3] N. Kumar, R.S. Mishra, W. Yuan, Friction Stir Welding of Dissimilar Alloys and Materials, Butterworth-Heinemann, 2015https://doi.org/10.1016/b978-0-12-802418-8. 00005-9.

[4] T. Tanaka, T. Morishige, T. Hirata, Scr. Mater. 61 (2009) 756-759, https://doi.org/10 1016/j.scriptamat.2009.06.022.

[5] T. Watanabe, H. Takayama, A. Yanagisawa, J. Mater. Process. Technol. 178 (2006) 342-349, https://doi.org/10.1016/j.jmatprotec.2006.04.117.

[6] W. Lee, M. Schmuecker, U.A. Mercardo, G. Biallas, S. Jung, Scr. Mater. 55 (2006) 355-358, https://doi.org/10.1016/j.scriptamat.2006.04.028.

[7] C. Chen, R. Kovacevic, Int. J. Mach. Tools Manuf. 44 (2004) 1205-1214, https://doi. org/10.1016/j.ijmachtools.2004.03.011.

[8] M. Yılmaz, M. Çöl, M. Acet, Mater. Charact. 49 (2002) 421-429, https://doi.org/10. 1016/S1044-5803(03)00051-2.

[9] T. Gendo, K. Nishiguchi, M. Asakawa, S. Tanioka, SAE. Technical. Paper. 01, 2007 1703, https://doi.org/10.4271/2007-01-1703.

[10] E. Taban, J.E. Gould, J.C. Lippold, Mater. Des. 31 (2010) 2305-2311, https://doi.org/ 10.1016/j.matdes.2009.12.010.

[11] Y. Hovanski, G. J. Glenn, S. Jana, K. F. Mattlin, U.S. Patent No. 8434661 (2007).

[12] T. Wang, H. Sidar, R.S. Mishra, Y. Hovanski, P. Upadhyay, B. Carlson, Sci. Technol. Weld. Join. 23 (2018) 249-255, https://doi.org/10.1080/13621718.2017.1381460.

[13] T. Wang, H. Sidar, R.S. Mishra, Y. Hovanski, P. Upadhyay, B. Carlson, Sci. Technol. Weld. Join. 24 (2019) 178-184, https://doi.org/10.1080/13621718.2018.1503801.

[14] B. Yang, J. Yan, M.A. Sutton, A.P. Reynolds, Mater. Sci. Eng. A 364 (2004) 55-65, https://doi.org/10.1016/S0921-5093(03)00532-X.

[15] R.M. Walser, R.W. Bené, Appl. Phys. Lett. 28 (1976) 624-625, https://doi.org/10. 1063/1.88590

[16] R.W. Bené, Appl. Phys. Lett. 41 (1982) 529-531, https://doi.org/10.1063/1.93578.

[17] R. Pretorius, A.M. Vredenberg, F.W. Saris, R. De Reus, J. Appl. Phys. 70 (1991) 3636-3646, https://doi.org/10.1063/1.349211.

[18] R. Pretorius, T.K. Marais, C.C. Theron, Mater. Sci. Rep. 10 (1993) 1-83, https://doi. org/10.1016/0920-2307(93)90003-W.

[19] C.C. Theron, O.M. Ndwandwe, J.C. Lombaard, R. Pretorius, Mater. Chem. Phys. 46 (1996) 238-247, https://doi.org/10.1016/S0254-0584(96)01805-6.

[20] R.W. Richards, R.D. Jones, P.D. Clements, H. Clarke, Int. Mater. Rev. 39 (1994) 191-212, https://doi.org/10.1179/imr.1994.39.5.191.

[21] R. Hultgren, P.D. Desai, D.T. Hawkins, M. Gleiser, K.K. Kelley, Selected Values of the Thermodynamic Properties of Binary Alloys, American Society for Metals, Metals Park, OH, 1973.

[22] R. Hultgren, P.D. Desai, D.T. Hawkins, M. Gleiser, K.K. Kelley, Selected Values of the Thermodynamic Properties of the Elements, American Society for Metals, Metals Park, OH, 1973.

[23] I. Ansara, A.T. Dinsdale, M.H. Rand, Thermochemical Database for Light Metal Alloys - COST 507, Office for Official Publications of the European Communities, 1998

[24] F.J. Perez, M.P. Hierro, J.A. Trilleros, M.C. Carpintero, L. Sanchez, F.J. Bolivar, Mater Chem. Phys. 97 (2006) 50-58, https://doi.org/10.1016/j.matchemphys.2005.07.076.

[25] H. Mehrer, Diffusion in Solid Metals and Alloys, Springer-Verlag, New York, 1990.

[26] S. Kobayashi, T. Yakou, Mater. Sci. Eng. A 338 (2002) 44-53, https://doi.org/10.1016/ S0921-5093(02)00053-9.

[27] S. Lin, J. Song, G. Ma, C. Yang, Front Mater Sci China 3 (2009) 78-83, https://doi.org/ 10.1007/s11706-009-0007-2.

[28] Z. Wan, H. Wang, N. Chen, M. Wang, B. Carlson, J. Mater. Process. Technol. 242 (2017) (2017) 12-23, https://doi.org/10.1016/j.jmatprotec.2016.11.017.

[29] S. Palanivel, A. Arora, K.J. Doherty, R.S. Mishra, Mater. Sci. Eng. A 678 (2016) 308-314, https://doi.org/10.1016/j.msea.2016.10.015.

[30] Z. Ma, A.L. Pilchak, M.C. Juhas, J.C. Williams, Scr. Mater. 58 (2008) 361-366, https:// doi.org/10.1016/j.scriptamat.2007.09.062. 